\title{
Restoring synaptic plasticity and memory in mouse models of Alzheimer's disease by PKR inhibition
}

\author{
Kyoung-Doo Hwang ${ }^{1 \dagger}$, Myeong Seong Bak ${ }^{2,3 \dagger}$, Sang Jeong Kim ${ }^{2,3,4}$, Sangmyung Rhee ${ }^{1 *}$ and Yong-Seok Lee $2,3,4^{*}$
}

\begin{abstract}
Alzheimer's disease (AD) is a neurodegenerative disorder associated with deficits in cognition and synaptic plasticity. While accumulation of amyloid $\beta(A \beta)$ and hyper-phosphorylation of tau are parts of the etiology, AD can be caused by a large number of different genetic mutations and other unknown factors. Considering such a heterogeneous nature of $A D$, it would be desirable to develop treatment strategies that can improve memory irrespective of the individual causes. Reducing the phosphorylation of eukaryotic translation initiation factor $2 a$ (elF2a) was shown to enhance long-term memory and synaptic plasticity in naïve mice. Moreover, hyperphosphorylation of elF2a is observed in the brains of postmortem AD patients. Therefore, regulating eIF2 $a$ phosphorylation can be a plausible candidate for restoring memory in AD by targeting memory-enhancing mechanism. In this study, we examined whether PKR inhibition can rescue synaptic and learning deficits in two different $A D$ mouse models; 5 XFAD transgenic and $A \beta_{1-42}$-injected mice. We found that the acute treatment of PKR inhibitor (PKRi) can restore the deficits in long-term memory and long-term potentiation (LTP) in both mouse models without affecting the $A \beta$ load in the hippocampus. Our results prove the principle that targeting memory enhancing mechanisms can be a valid candidate for developing AD treatment.
\end{abstract}

Keywords: Alzheimer's disease (AD), Amyloid $\beta$ (Aß), PKR inhibitor (PKRi), Contextual fear conditioning, Object recognition memory, Long-term potentiation (LTP)

\section{Introduction}

Alzheimer's disease (AD) is a neurodegenerative disorder characterized by cognitive deficits and synaptic dysfunction, for which there is currently no effective treatment available. Genetic studies have shown that mutations in specific set of genes such as APP, PSEN1, and PSEN2 are associated with early-onset of familial AD (FAD) [1-3]. $A P P$ encodes amyloid $\beta(\mathrm{A} \beta)$ precursor protein, while PSEN1 and PSEN2 encodes presenilin-1 and presenilin2 , respectively. These proteins are involved in $A \beta$ processing pathway and consequently support a hypothesis that $A \beta$ accumulation in the brain is critical for the

\footnotetext{
* Correspondence: sangmyung.rhee@cau.ac.kr; yongseok7@snu.ac.kr ${ }^{\dagger}$ Equal contributors

'Department of Life Science, College of Natural Science, Chung-Ang University, Seoul 06974, Republic of Korea

${ }^{2}$ Department of Physiology, Seoul National University College of Medicine,

Seoul 03080, Republic of Korea

Full list of author information is available at the end of the article
}

onset of $\mathrm{AD}$ [4]. In addition to $\mathrm{A} \beta$ accumulation, hyperphosphorylation of tau is another well-known hallmark for $\mathrm{AD}$ [5]. Interestingly, both $\mathrm{A} \beta$ accumulation and tau hyper-phosphorylation are regulated by eukaryotic translation initiation factor $2 \alpha(\mathrm{eIF} 2 \alpha)[6,7]$. Hyperphosphorylation of eIF $2 \alpha$ at Ser 51 is observed in the brains of postmortem AD patients as well as in several $\mathrm{AD}$ mouse models [8-11]. In addition, $\mathrm{A} \beta$ treatment was shown to induce the phosphorylation of eIF $2 \alpha$ in cultured neurons [12]. Whereas the phosphorylation of eIF $2 \alpha$ inhibits general mRNA translation, eIF $2 \alpha$ phosphorylation enhances translation of the specific group of mRNAs such as $\beta$-site APP cleaving enzyme 1 (BACE1) and activating transcriptional factor 4 (ATF4), a suppressor of memory formation by inhibiting cAMP responsive element binding protein (CREB)-dependent transcription [12-14]. Since CREB is essential for long-term memory formation and long-term synaptic plasticity [15-18], reducing eIF2 $\alpha$ phosphorylation enhanced long-term 
potentiation (LTP) and long-term memory by reducing ATF4 translation in mice [19]. In addition to eIF2 $\alpha$, the double-stranded RNA-activated protein kinase (PKR), one of eIF $2 \alpha$ kinases, is highly phosphorylated in AD brains $[7,11,20]$. PKR becomes active through the auto-phosphorylation when it binds to ATP and dsRNA [21]. Previous studies revealed that either genetic or pharmacological blockage of PKR enhances LTP and memory in mice $[22,23]$.

Recent studies have suggested that reducing the phosphorylation level of eIF2 $\alpha$ could be one of treatment strategies for $\mathrm{AD}[9,10,13,24]$. Genetic reduction of PERK and GCN2, which are other kinases of eIF2 $\alpha$, ameliorated AD-related phenotypes in synaptic plasticity and behavior in AD mouse models such as APP/PS1 mice and 5XFAD mice $[9,10]$ (but also see [8]). However, most of the previous studies focused on eIF $2 \alpha$ signaling pathway in mainly relation to the production of $\mathrm{A} \beta[8-10,13]$.

We hypothesized that PKR inhibition may enhance synaptic plasticity and subsequently rescue memory deficits in $\mathrm{AD}$ mouse models even at late stage of the disease. We used $\mathrm{A} \beta_{1-42}$-injected wild-type mice and 5XFAD transgenic mice as acutely induced and genetic model of $\mathrm{AD}$, respectively $[25,26]$. Our data showed that PKR inhibitor (PKRi) restored LTP deficit in both AD mouse models. Moreover, we found that PKRi treatment rescued the hippocampus-dependent memory deficits in both mouse models. In addition, acute PKR inhibition did not cause any change in $A \beta$ load in the hippocampus of 5XFAD mice. Taken together, this study suggests that enhancing synaptic plasticity by targeting PKR-eIF2 $\alpha$ signaling pathway can be a potential therapeutic target for AD.

\section{Results}

PKRi treatment rescues the contextual fear memory deficit in SXFAD mice

We first examined whether PKR inhibitor (PKRi, C-16) treatment can reverse memory deficits in 5XFAD mice which overexpress human mutant forms of APP and PS1 [25]. It is well known that 5XFAD mice show A $\beta$ deposition as early as 2 months after birth and exhibit deficits in memory and LTP after 6 months old [25, 27]. We tested 5XFAD mice ( 12 months old) in contextual fear conditioning (CFC) which is a hippocampusdependent associative learning and memory task [2830]. 5XFAD mice showed profound contextual fear memory deficit at $24 \mathrm{~h}$ after training compared with wild-type (WT) littermates (Fig. 1). Interestingly, PKRi treatment (i.p. $0.335 \mathrm{mg} / \mathrm{kg}, 20 \mathrm{~min}$ before training) significantly enhanced freezing in 5XFAD mice without affecting the freezing level in WT littermates (Fig. 1; \% freezing: WT, $49.03 \pm 6.67 \%, n=9$ mice; WT + PKRi, $46.78 \pm 5.90 \%, n=10$ mice; $5 X F A D, 8.74 \pm 4.18 \%, n=6$

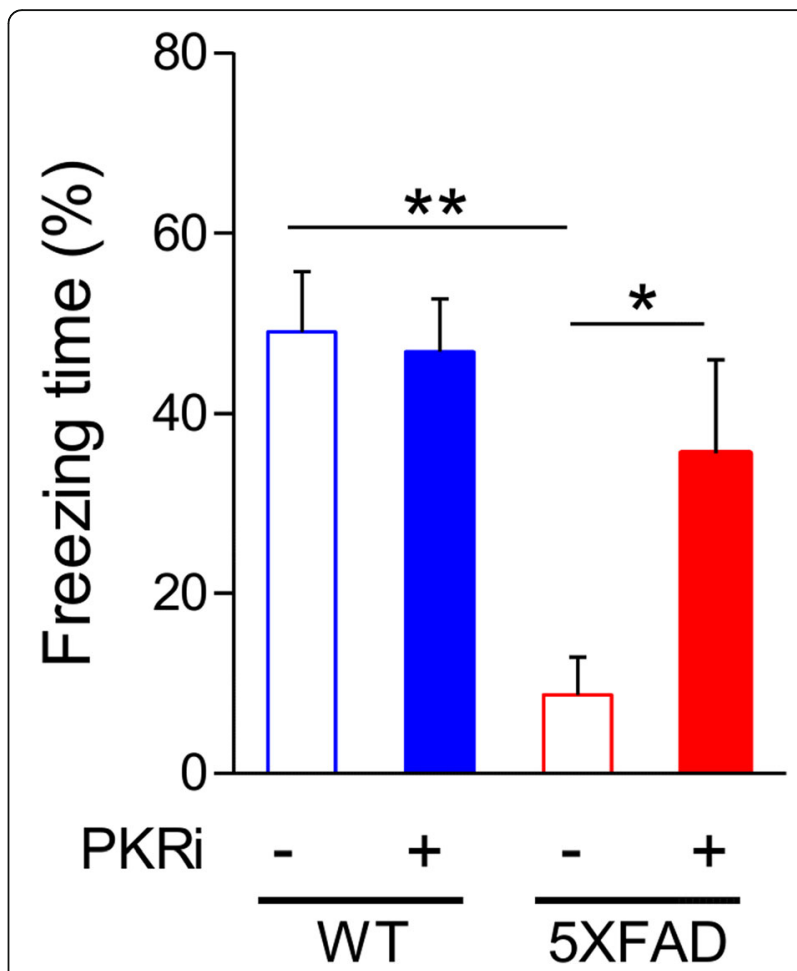

Fig. 1 PKRi treatment rescues fear memory deficit in 5XFAD mice. Eleven to twelve months old 5XFAD mice showed significant deficit in contextual fear memory, which was rescued by PKRi treatment $(0.335 \mathrm{mg} / \mathrm{kg})$ (\% freezing: WT, $49.03 \pm 6.67 \%, n=9$ mice; $W T+$ PKRi, $46.78 \pm 5.90 \%, n=10$ mice; 5 XFAD, $8.74 \pm 4.18 \%, n=6$ mice; $5 X F A D+$ PKRi, $35.55 \pm 10.38 \%, n=7$ mice; Two-way ANOVA, interaction between genotype and PKRi, $p=0.0558$, Bonferroni posttests, ${ }^{*} p<0.05$, ${ }^{* *} p<0.01$ ). Bars represent as mean \pm SEM

mice; 5XFAD + PKRi, $35.55 \pm 10.38 \%, n=7$ mice; Twoway ANOVA, interaction between genotype and PKRi, $\mathrm{F}(1,29)=2.19, p=0.056$; Bonferroni post-tests, ${ }^{*} p<0.05$, $* p<0.01)$, demonstrating that PKR inhibition can rescue the memory deficit in the transgenic mouse model of $\mathrm{AD}$ even when the mice are one year old.

\section{PKR inhibition restores hippocampal synaptic plasticity in 5XFAD mice}

Long-term potentiation (LTP) is considered as a cellular mechanism for long-term memory [31]. Accordingly, LTP deficits have been reported in AD mouse models including 5XFAD mice $[9,27]$. We examined whether PKRi can also reverse the LTP deficit in the hippocampal Schaffer-collateral pathway in 5XFAD mice. PKRi $(1 \mu \mathrm{M}$, $0.002 \%$ DMSO) was treated from 40 min before LTP induction (theta burst stimulation, TBS: 4 pulses at $100 \mathrm{~Hz}, 200 \mathrm{~ms}$ inter-burst intervals) and throughout the recording. We found that PKRi treatment restored the deficit in TBS-induced LTP in hippocampal slices from 5XFAD mice without affecting LTP in wild-type slices (Fig. 2; Average fEPSP slope, last $10 \mathrm{~min}$ : WT, $147.77 \pm 2.19 \%, n=6$ slices from 4 mice; WT and PKRi, 

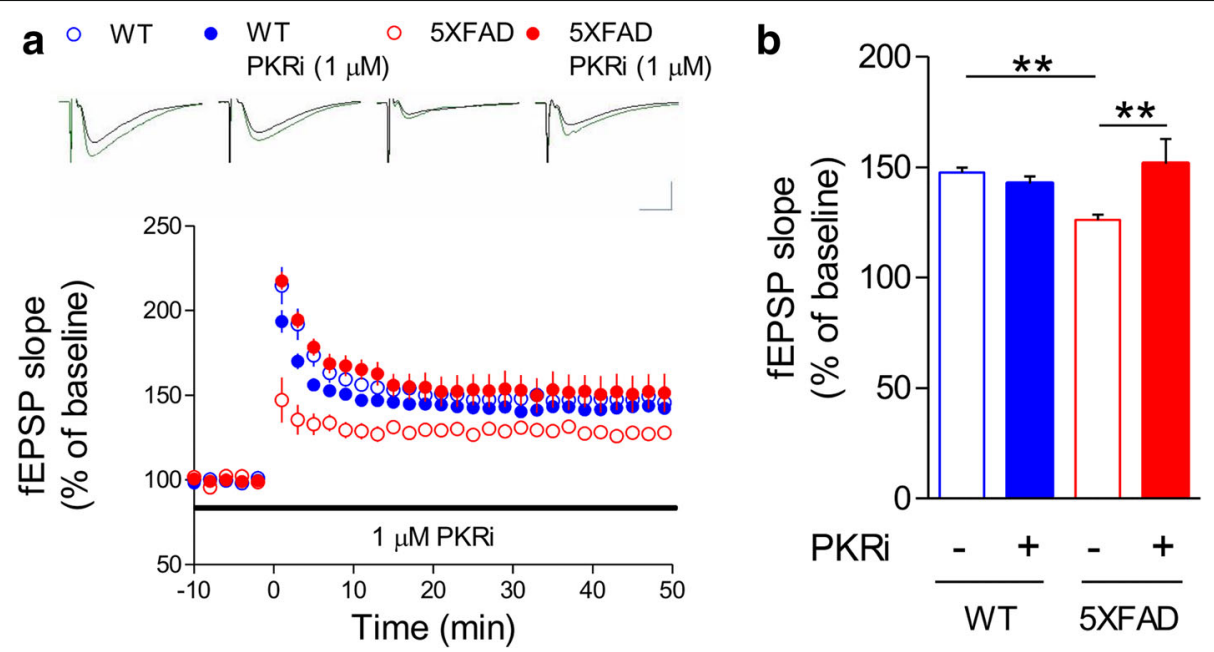

Fig. 2 Inhibition of PKR restores LTP impairment in 5XFAD mice. a LTP in Schaffer-collateral-CA1 pathway was induced by theta burst stimulation (TBS). Field excitatory synaptic potential (fEPSP) slopes were normalized by the average of baseline recordings. Slices from 5XFAD mice showed significantly reduced LTP than WT, which can be restored by PKRi treatment (1 $\mu \mathrm{M}, 90 \mathrm{~min})$. Representative traces were shown above. Black, baseline; Green, average between 40 and 50 min after TBS. Vertical bar, $1.0 \mathrm{mV}$; horizontal bar, $5 \mathrm{~ms}$. b Cumulative data showing the average field excitatory synaptic potential (fEPSP) slope of 40-50 min after TBS (WT, 147.77 $\pm 2.19 \%, n=6$ slices from 4 mice; WT + PKRi, $142.83 \pm 3.10 \%, n=9$ slices from 5 mice; 5 XFAD, $126.22 \pm 2.36 \%, n=7$ slices from 5 mice; $5 X F A D$ and PKRi, $151.67 \pm 11.20 \%, n=5$ slices from 3 mice; Two-way ANOVA, interaction between genotype and PKRi, ${ }^{*} p<0.05$, Two-way ANOVA, Bonferroni post-tests, ${ }^{* *} p<0.01$ ). Bars represent as mean \pm SEM

$142.83 \pm 3.10 \%, n=9$ slices from 5 mice; 5 XFAD, 126.22 $\pm 2.36 \%, n=7$ slices from 5 mice; 5XFAD and PKRi, $151.67 \pm 11.20 \%, n=5$ slices from 3 mice; Two-way ANOVA, interaction between genotype and PKRi, F(1, $23)=9.997, * p<0.05$; Bonferroni post-tests; $\left.{ }^{* *} p<0.01\right)$. In addition to LTP, we also examined whether basal synaptic properties are altered in 5XFAD mice (Additional file 1: Fig. S2). Input-output (I-O) relationship analysis showed that 5XFAD mice have significantly reduced basal synaptic transmission (Additional file 1: Fig. S2A; Two-way ANOVA, Bonferroni post-tests, WT vs $5 \mathrm{XFAD},{ }^{* * * * *} p<0.001$ in the range of $40-100 \mu \mathrm{A}$; WT, $n$ $=25$ slices from 11 mice; 5XFAD, $n=16$ slices from 8 mice), whereas the presynaptic fiber volley amplitudes were not different among groups (Additional file 1: Figure S2B). Moreover, paired pulse facilitation ratio (PPR) was also significantly reduced in 5XFAD mice compared to wild-type littermates (Additional file 1: Figure S2C; Two-way ANOVA, Bonferroni post-tests; WT vs $5 \mathrm{XFAD},{ }^{*} p<0.05$ in 25 and $50 \mu \mathrm{A}$; WT, $n=22$ slices from 11 mice; 5 XFAD, $n=15$ slices from 8 mice). Interestingly, PKRi treatment for 30 min rescued the deficits in basal synaptic transmission and PPR in 5XFAD (I-O: Two-way ANOVA, Bonferroni post-tests; 5XFAD vs $5 \mathrm{XFAD}+\mathrm{PKRi}(1 \mu \mathrm{M}), \# p<0.05$ in the range of $70-$ $100 \mu \mathrm{A} ; 5 \mathrm{XFAD}, n=16$ slices from 8 mice; 5XFAD and PKRi, $n=7$ slices from 4 mice; Additional file 1 : Figure S2A; PPR: Two-way ANOVA, Bonferroni posttests, 5XFAD vs 5XFAD + PKRi $(1 \mu \mathrm{M})$, \#\#p 0.01 in $25 \mu \mathrm{A}, \# p<0.05$ in $50 \mu \mathrm{A}$; 5XFAD, $\mathrm{n}=15$ slices from
8 mice; 5XFAD and PKRi, $\mathrm{n}=7$ slices from 4 mice; Additional file 1: Figure S2C).

PKRi treatment does not decrease $A \beta_{1-42}$ in the hippocampus of 5XFAD mice

Previous studies focused on the effect of genetic suppression of eIF $2 \alpha$ phosphorylation on $A \beta$ generation $[8-10,13]$. We asked whether acute treatment of 5XFAD mice with PKRi reduced $A \beta$ in the hippocampus. We found significantly higher amount of $A \beta_{1-42}$ oligomers such as dimers and tetramers in the hippocampus of 5XFAD mice compared with WT littermates (Fig. 3A). Interestingly, we found that $\mathrm{A} \beta_{1-42}$ oligomers were not decreased by PKRi treatment (Fig. 3B, C; dimer levels normalized by that of vehicle-injected 5XFAD; vehicle, 0 ; vehicle + PKRi, $0 ; A \beta_{1-42}, 1.00 \pm 0.15 ; A \beta_{1-42}+$ PKRi, $1.18 \pm 0.06$; unpaired t-test, 5 XFAD vs $5 \mathrm{XFAD}+\mathrm{PKRi}, p=$ 0.2674 ; tetramer levels normalized by that of vehicleinjected 5XFAD; vehicle, 0 ; vehicle + PKRi, 0 ; $A \beta_{1-42}, 1.00$ $\pm 0.13 ; \mathrm{A} \beta_{1-42}+\mathrm{PKRi}, 1.28 \pm 0.23$; unpaired t-test, $5 \mathrm{XFAD}$ vs $5 \mathrm{XFAD}+\mathrm{PKRi}, p=0.3243 ; 6$ hippocampi from 3 mice per group). These findings suggest that the acute effect of PKRi on LTP and memory is not based on regulating the amyloidogenesis.

PKR inhibition rescues memory deficit in $A \beta_{1-42}$-injected mice To investigate whether PKR inhibition can be a general strategy to restore synaptic plasticity and memory in multiple AD mouse models, we examined the effect of PKRi on memory in $A \beta_{1-42}$-injected mice. We tested 


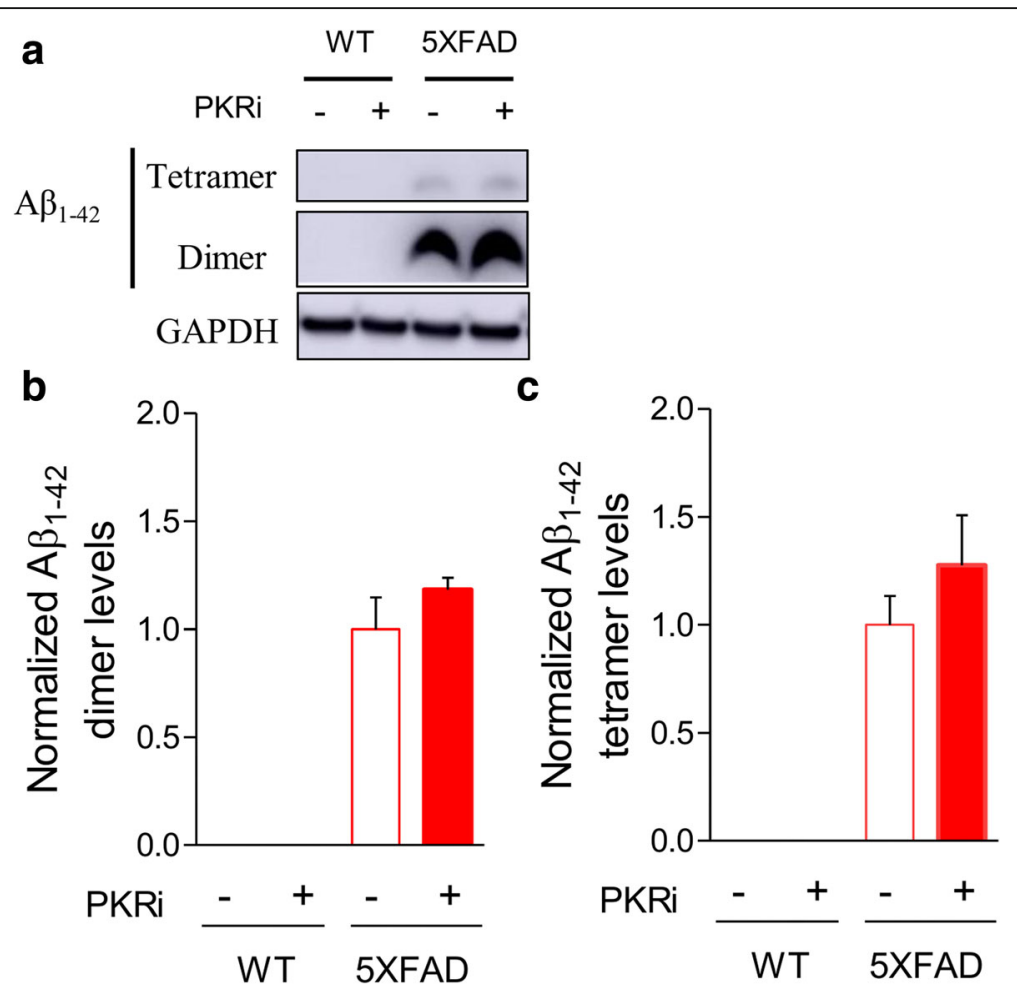

Fig. 3 PKRi treatment does not decrease $A \beta_{1-42}$ in the hippocampus of 5XFAD mice. a Representative immunoblots of protein extracts from the hippocampi $1 \mathrm{~h}$ after PKRi injection $(0.335 \mathrm{mg} / \mathrm{kg})$ in WT and 5XFAD mice. b, c Quantification of the of A $\beta_{1-42}$ oligomers such as dimers and tetramers showing that PKRi treatment did not affect $A \beta_{1-42}$ oligomers in 5XFAD mice (dimer levels normalized by that of 5XFAD; vehicle, 0; vehicle + PKRi, $0 ; A \beta_{1-42}, 1.00 \pm 0.15 ; A \beta_{1-42}+$ PKRi, 1.18 \pm 0.06 ; unpaired t-test, 5 XFAD vs 5XFAD + PKRi, $p=0.2674$; tetramer levels normalized by that of 5XFAD; vehicle, 0 ; vehicle + PKRi, $0 ; A \beta_{1-42}, 1.00 \pm 0.13 ; A \beta_{1-42}+$ PKRi, $1.28 \pm 0.23$; unpaired t-test, 5XFAD vs 5XFAD + PKRi, $p=0.3243 ; 6$ hippocampi from 3 mice per group). Bars represent as mean \pm SEM

contextual fear memory in vehicle- or $A \beta_{1-42}$-injected wild-type ICR mice (Additional File 1: Figure S3). Unexpectedly, we found that the freezing levels of both groups were low, which makes it difficult to compare freezing levels among different groups $\left(3 \mu \mathrm{g} / 3 \mu \mathrm{l} \mathrm{A} \beta_{1-42}\right.$, i.c.v. injection, Vehicle, $n=8$ mice, 24 h, $6.23 \pm 2.21 \%$; $\mathrm{A} \beta_{1-42}, \mathrm{n}=8$ mice, $\left.24 \mathrm{~h}, 7.359 \pm 5.79 \%\right)$. Therefore, we used the novel object recognition (NOR) task, which has been frequently used to examine AD-related memory deficits in mice [32]. Since the same mice can be repeatedly tested by replacing object set and long-term memory can be acquired by a single training trial, NOR is frequently used to test effects of pharmacological interventions on learning and memory [33]. We trained the mice in NOR task 2 days after $A \beta_{1-42}$ infusion and tested long-term memory $24 \mathrm{~h}$ after the training. As previously reported [34], $A \beta_{1-42}$-injected mice showed significant NOR memory deficit compared to vehicleinjected control mice (Fig. 4). Importantly, PKR inhibitor (PKRi, $0.335 \mathrm{mg} / \mathrm{kg}$ ) treatment $20 \mathrm{~min}$ before the training significantly improved the long-term NOR memory in $\mathrm{A} \beta_{1-42}$-injected mice (Fig. 4; preference index for the novel object: Vehicle, $61.33 \pm 2.86 \%$; PKRi, $60.92 \pm 0.84 \%$;
$\mathrm{A} \beta, \quad 49.09 \pm 3.21 \% ; \quad \mathrm{A} \beta_{1-42}$ and PKRi, $62.70 \pm 2.80 \%$; Two-way ANOVA, interaction between $A \beta_{1-42}$ and PKRi, $\mathrm{F}(1,10)=9.067, " p<0.05$; Bonferroni post-tests, $" p<0.05, " * p<0.01, n=6$ mice for each group), suggesting that inhibiting PKR during training can rescue longterm memory deficit in $A \beta_{1-42}$-injected mice.

\section{PKR inhibition restores the $A \beta_{1-42}$-induced LTP impairment in hippocampus}

As previously reported, $A \beta_{1-42}$-treated hippocampal slices showed impaired LTP compared to vehicle-treated slices (Fig. 5A, B) [35, 36]. To test the effect of PKR inhibition on LTP, PKRi ( $1 \mu \mathrm{M}, 0.002 \%$ DMSO $)$ was treated from 30 min before LTP induction $(2 \mathrm{X} 100 \mathrm{~Hz}$ stimulation, $30 \mathrm{~s}$ interval) until $30 \mathrm{~min}$ after LTP induction. We found that PKRi treatment significantly enhanced LTP in $A \beta_{1-42}$-treated hippocampal slices whereas it did not affect LTP in control slices (Vehicle, $143.52 \pm 5.22 \%, n=7$ slices from 6 mice; PKRi, 144.48 $\pm 9.73 \%, \mathrm{n}=7$ slices from 5 mice; $\mathrm{A} \beta_{1-42}, 118.00 \pm$ $2.99 \%, n=12$ slices from 8 mice; $A \beta_{1-42}$ and PKRi, $146.28 \pm 9.45 \%, \mathrm{n}=7$ slices from 7 mice; Two-way ANOVA, interaction between $A \beta_{1-42}$ and PKRi, $F(1,23)$ 


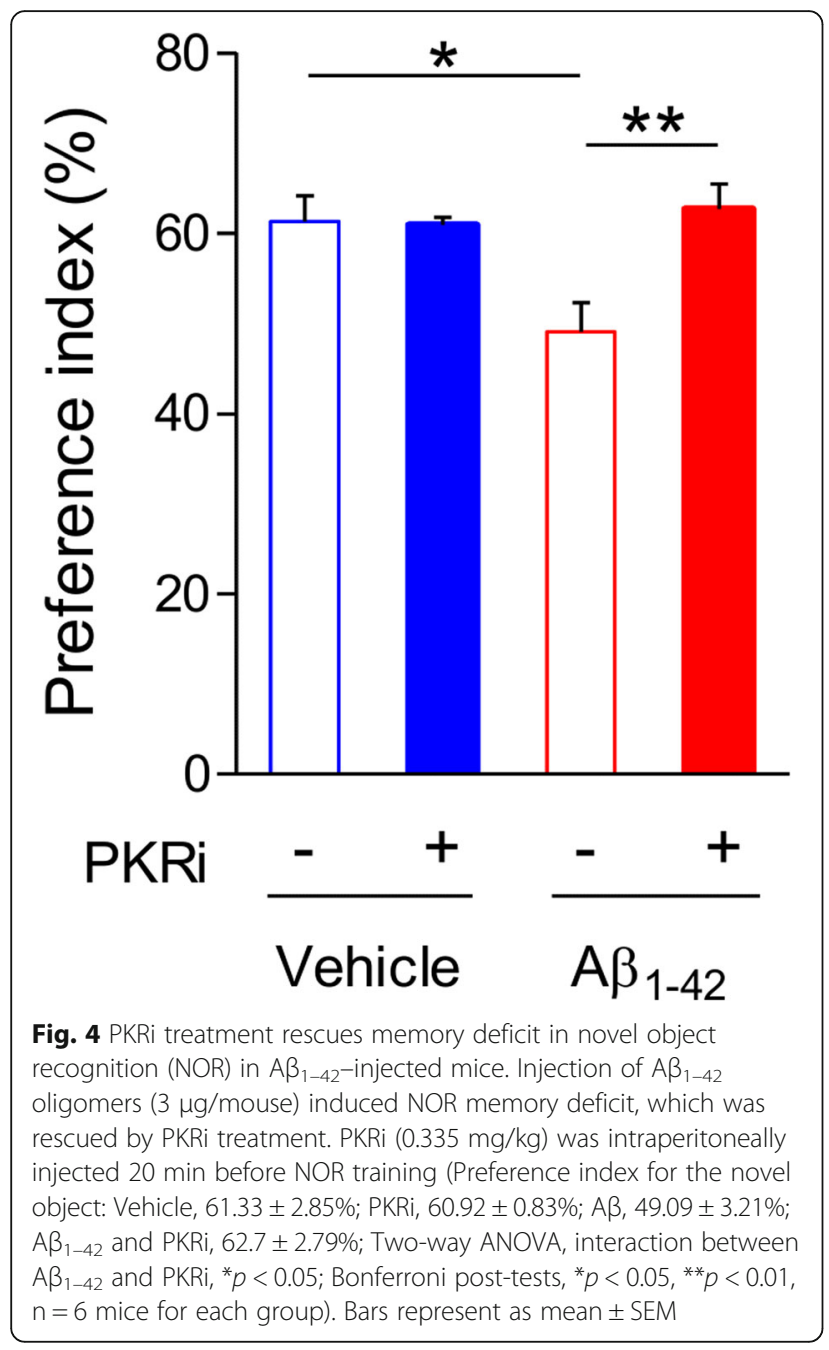

$=4.213, " p<0.05$; Bonferroni post-tests, ${ }^{*} p<0.05,{ }^{* * *} p<$ 0.01 ), suggesting that PKR inhibition can rescue LTP deficit in $A \beta_{1-42}$-treated hippocampus (Fig. 5A, B). Neither $A \beta_{1-42}$ nor PKRi treatment affected basal synaptic properties including I-O relationship, fiber volley amplitude and PPR (Additional file 1: Figure S4).

PKRi treatment has a trend to reverse $A \beta_{1-42}$-mediated changes in PKR signaling

In order to provide insight into the molecular mechanism underlying PKRi-induced restorations of memory and LTP, we analyzed the phosphorylation levels of PKR, eIF $2 \alpha$ and CREB by performing western blot analyses (Fig. 6A). The level of PKR phosphorylation was increased by $A \beta_{1-42}$ and was reversed by PKRi treatment although the effect of PKRi was not statistically significant (Fig. 6B; normalized p-PKR, vehicle, $1.00 \pm 0.05,14$ hippocampi from 11 mice; $A \beta_{1-42}, 1.22 \pm 0.09,15$ hippocampi from 13 mice; $\mathrm{A} \beta_{1-42}+\mathrm{PKRi}, 1.01 \pm 0.06,14$ hippocampi from 11 mice; unpaired t-test, vehicle vs $\mathrm{A} \beta_{1-42}, p=0.055 ; \mathrm{A} \beta_{1-42}$ vs $\left.\mathrm{A} \beta_{1-42}+\mathrm{PKRi}, p=0.089\right)$. Consistently, eIF $2 \alpha$ phosphorylation (p-eIF $2 \alpha$ ) was significantly increased in $A \beta_{1-42}$-treated mice (Fig. 6C; normalized p-eIF $2 \alpha$, vehicle, $1.00 \pm 0.04 ; \mathrm{A} \beta_{1-42}, \quad 17$ hippocampi from 11 mice, $1.28 \pm 0.11,19$ hippocampi from 13 mice; unpaired t-test, $\left.{ }^{*} p<0.05\right)$. Importantly, PKRi treatment mildly decreased eIF $2 \alpha$ phosphorylation in $A \beta_{1-42}$-treated mice but the effect did not reach the statistical significance (Fig. 6C; $\mathrm{A} \beta_{1-42}, 1.28 \pm 0.11,19$ hippocampi from 13 mice; $\mathrm{A} \beta_{1-42}+\mathrm{PKRi}, 1.14 \pm 0.10,18$ hippocampi from 12 mice; unpaired t-test, $A \beta_{1-42}$ vs $\left.\mathrm{A} \beta_{1-42}+\mathrm{PKRi}, \quad p=0.354\right)$. Neither $\mathrm{A} \beta_{1-42}$ nor PKRi treatment did not cause any significant change in CREB
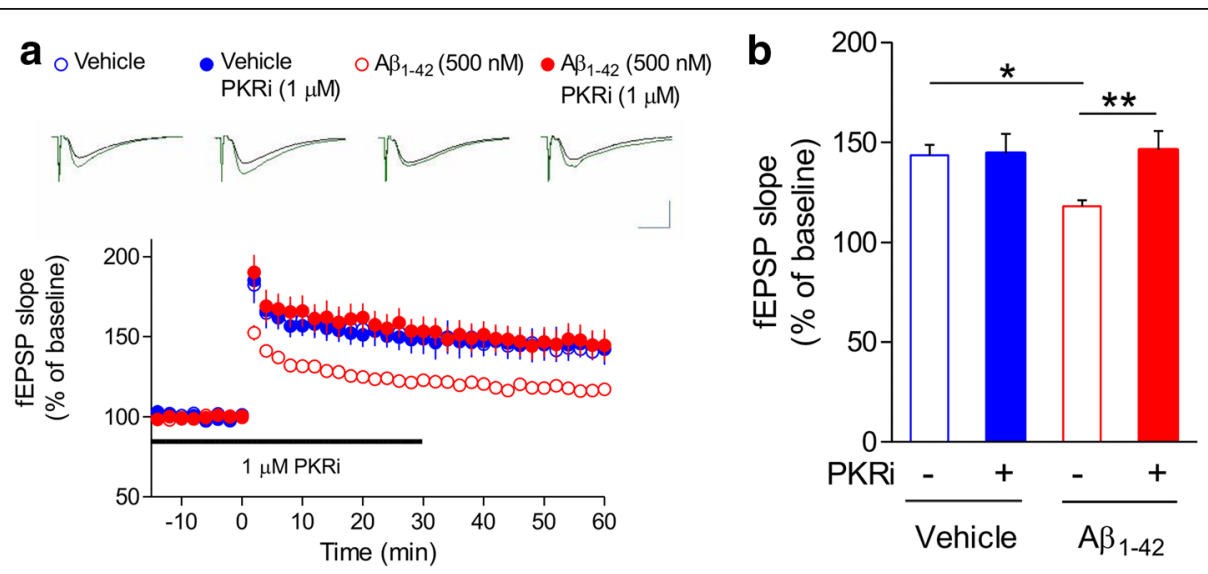

Fig. 5 Inhibition of PKR restores $A \beta_{1-42}$-induced LTP impairment in hippocampus. a PKRi treatment rescued the LTP deficit in $A \beta_{1-42}$-treated slices. $A \beta_{1-42}$ (500 nM) was treated for $2 \mathrm{~h}$ before recording and PKRi (1 $\mu \mathrm{M})$ was applied for $1 \mathrm{~h}$ (30 min before/after LTP induction). Representative traces were shown above. Black, baseline; Green, average between 40 and 50 min after HFS. Vertical bar, 1.0 mV; horizontal bar, 5 ms. b Cumulative data showing the average field excitatory synaptic potential (fEPSP) slope of 50-60 min after LTP induction (2X HFS) Vehicle, 143.52 $\pm 5.22 \%, \mathrm{n}=7$ slices from 6 mice; PKRi, 144.48 $\pm 9.73 \%, n=7$ slices from 5 mice; $A \beta_{1-42}, 118.00 \pm 2.99 \%, n=12$ slices from 8 mice; $A \beta_{1-42}$ and PKRi, $146.28 \pm 9.45 \%, n=7$ slices from 7 mice; Two-way ANOVA, interaction between $A \beta_{1-42}$ and PKRi, ${ }^{*} p<0.05$, Two-way ANOVA, Bonferroni post-tests, ${ }^{*} p<0.05$, ${ }^{* *} p<0.01$ ). Bars represent as mean \pm SEM 


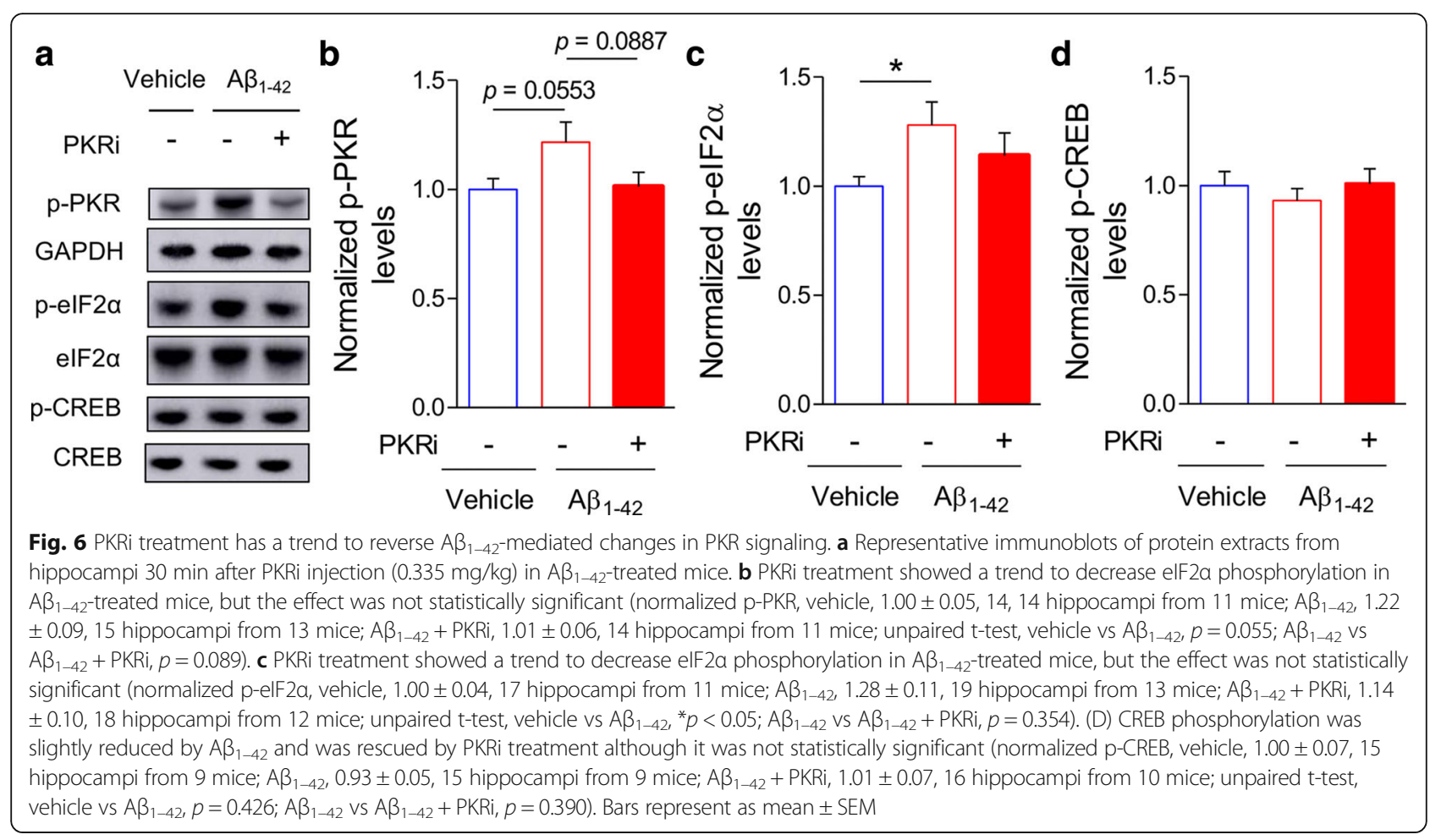

phosphorylation (p-CREB) levels, although $A \beta_{1-42}$ treatment slightly decreased p-CREB level (Fig. 6D; normalized $\mathrm{p}$-CREB, vehicle, $1.00 \pm 0.07,15$ hippocampi from 9 mice; $\mathrm{A} \beta_{1-42}, 0.93 \pm 0.05,15$ hippocampi from 9 mice; $\mathrm{A} \beta_{1-42}+\mathrm{PKRi}, 1.01 \pm 0.07,16$ hippocampi from 10 mice; unpaired t-test, vehicle vs $\mathrm{A} \beta_{1-42}, p=0.426 ; \mathrm{A} \beta_{1-42}$ vs $\mathrm{A} \beta_{1-42}+$ PKRi, $\left.p=0.390\right)$.

\section{Discussion}

$\mathrm{AD}$ is a highly heterogeneous disease caused by multiple known and unknown factors. Therefore, it would be extremely difficult to develop treatments by targeting specific causes for individual cases. Based on a hypothesis that manipulating memory-enhancing mechanisms may be beneficial to $\mathrm{AD}$ animal models irrespective of their individual etiology $[18,31]$, we examined whether suppressing PKR/eIF2 $\alpha$ signaling can restore synaptic plasticity and behaviors in $\mathrm{AD}$ mouse models. It has been previously shown that inhibiting eIF2 $\alpha$ phosphorylation can enhance synaptic plasticity and memory in mice [19, $22,23,37]$. Our results in the electrophysiological recording show that impaired synaptic plasticity can be rescued by PKRi in two different AD mouse models. We assume that these changes in synaptic plasticity consequently contributed to restoring the memory deficit in AD mouse models. Suppressing eIF2 $\alpha$ phosphorylation was shown to enhance CREB activity as well as LTP by reducing the translation of ATF4 [19, 38]. It is also known that elevated CREB activity increases the density and complexity of dendritic spines and enhances presynaptic neurotransmitter release [39, 40]. A previous study showed that overexpression of CREB in CA1 rescued spatial memory deficit and altered structure of dendritic spines in 5XFAD mice, which had lower level of CREB phosphorylation [40]. However, we found that pCREB level was slightly, but not statistically significantly altered by either $A \beta_{1-42}$ or PKRi treatment in the hippocampus under our experimental condition. Although further experiments are required, we speculate that our sample preparation time ( 2 days after $A \beta_{1-42}$-injection, 30 min after PKRi injection) might not be optimal to observe the impact of $A \beta_{1-42}$-injection and PKR inhibition on CREB phosphorylation.

Previous studies have reported that genetic disruption of PERK in AD mouse models such as APP/PS1 and 5XFAD mice can rescue AD-associated phenotypes, suggesting that inhibiting the upstream kinase of eIF2 $\alpha$ may be beneficial to $\operatorname{AD}[9,10,13]$. In contrast, there is an inconsistency in the effect of genetic disruption of GCN2 on AD mouse models $[8,9]$. Ma and colleagues found that the conditional knockout of GCN2 rescued the deficits in LTP and spatial memory in APP/PS1 mice [9], whereas Devi and Ohno showed that GCN2 deletion could not rescue AD-related phenotypes in 5XFAD mice [8]. Moreover, crossing 5XFAD to eIF2 $\alpha^{\mathrm{S} 51 \mathrm{~A}}$ knock-in line failed to rescue memory deficits in 5XFAD mice [41]. These findings suggest that manipulation of different eIF2 $\alpha$ kinases may have distinct impact on cognitive 
functions in AD mouse models. A recent study showed that PKRi treatment rescued memory deficits in an AD mouse model expressing the human APOE4 allele, which is consistent with our results [24]. However, to our knowledge, our data is the first showing the beneficial effect of PKRi on synaptic plasticity as well as memory in two independent $\mathrm{AD}$ mouse models, which might support the possibility that PKRi could be a potential broad-spectrum drug for $\mathrm{AD}$ treatment.

We found that PKR inhibition also reversed the deficits in basal synaptic transmission and short-term plasticity assessed by PPR in 5XFAD mice. Zhu and colleagues recently showed that PKRi treatment in naïve mice decreased GABAergic output of inhibitory networks, resulting the hyperactivity of excitatory neuronal networks [22]. A previous study showed that 5XFAD mice had lower activity of excitatory neural networks compared to their WT littermates [42], which may contribute to the deficits in basal synaptic transmission in 5XFAD mice. We also found that 5XFAD mice showed LTP deficit only when LTP was induced by TBS protocol which is more sensitive to changes in inhibition, but not by high frequency stimulation $(100 \mathrm{~Hz})$ protocol (Additional file 1: Figure S5) [43], suggesting an imbalance between excitation and inhibition in 5XFAD mice. It is plausible to speculate that PKRi might have rescued the deficits in basal synaptic transmission and long-term synaptic plasticity by restoring the activity of excitatory networks although it remains to be further investigated. Furthermore, it is worthy to note that changes in inflammation processes involving interferon gamma may underlie the beneficial effect of PKRi on AD mouse models since it has been reported that genetic deletion or inhibition of PKR upregulates the level of interferon gamma, which in turn increases neural excitability and enhances cognitive functions [22, 44].

In contrast to previous studies $[19,22]$, PKRi treatment did not enhance LTP or learning in our study. Although the reason for the difference is not clear, different experimental conditions such as genetic background of the mice (ICR or B6SJL in our study vs. $\mathrm{C} 57 \mathrm{Bl} / 6 \mathrm{~J}$ in [19]) may contribute to the difference. Also, Segev and colleagues did not see the memory enhancement in control ApoE3 mice [24].

It is worthy to note that we could rescue the deficits in 12-month-old 5XFAD mice by acute PKRi treatment, suggesting that PKRi might be effective in late stage of $\mathrm{AD}$ in spite of the substantial accumulation of amyloid $\beta$ in the brain. Indeed, we showed that acute PKRi treatment can reverse deficits in LTP and memory in 5XFAD mice without affecting $A \beta$ load in the hippocampus. Considering recent reports on failures in AD clinical trials by targeting amyloid $\beta[45,46]$ (but also see [47]), pharmacological interventions enhancing plasticity such as suppressing PKR may provide a promising alternative strategy for developing AD treatment.

\section{Methods \\ Animals}

4-6-week-old male ICR mice were purchased from Orient Bio Inc. and B6SJL-Tg (APPSwFlLon, PSEN1*M146 L*L286V)6799Vas/Mmjax mice (5XFAD) were generous gifts from Dr. Woo Keun Song (Gwangju Institute of Science and Technology, Korea) and Dr. Inhee Mook-Jung (Seoul National University College of Medicine, Korea). Both male and female 5XFAD mice were used. Mice were maintained on a $12 \mathrm{~h}$ light-dark cycle and food and water were provided ad libitum in vivarium at Seoul National University College of Medicine and Chung-Ang University. Mice were assigned in a group of 4 to 6 per cage and acclimated to the vivarium at least one week before experiments. Prior to experiments, mice were individually handled for $5 \mathrm{~min}$ in the testing room each day for 4 days.

\section{Preparation of $A \beta_{1-42}$ oligomers}

A $\beta_{1-42}$ (Abcam, Catalog \# ab120301, Lot \# APN151581-2) peptide was dissolved in $1 \mathrm{ml}$ of hexafluoroisopropanol (HFIP, Sigma) for $24 \mathrm{~h}$ on a rocker at room temperature. HFIP was slowly evaporated by using nitrogen gas [36]. Dried $A \beta_{1-42}$ pellet was dissolved in DMSO (final concentration, 4.4 mM, Duchefa, D1370) and immediately frozen with dry ice and stored at $-80{ }^{\circ} \mathrm{C}$. In order to oligomerize, $A \beta_{1-42}$ stock was diluted in DPBS (WELGENE, LB001-02) to final DMSO concentrations of $10 \%$, then incubated for $24 \mathrm{~h}$ at $37{ }^{\circ} \mathrm{C}$ [26]. The $\mathrm{A} \beta_{1-}$ 42 oligomers were analyzed by western blot (Additional file 1: Figure S1) and BCA assay (Thermo pierce).

\section{PKRi treatment}

PKRi (C-16, Cal-biochem, \# 527450) stock solution was dissolved in DMSO $(670 \mu \mathrm{g} / \mathrm{ml})$. For behavioral test, PKRi were further diluted in distilled water to a final DMSO concertation of $10 \%$ immediate before i.p. injection $(0.335 \mathrm{mg} / \mathrm{kg}$ body weight). For control group, 10\% DMSO in distilled water was used as vehicle. For electrophysiology, PKRi was diluted in ACSF to $1 \mu \mathrm{M}$.

\section{Stereotaxic surgery}

Mice were anesthetized with the mixture of ketamine $(133 \mathrm{mg} / \mathrm{kg})$ and xylazine $(10.5 \mathrm{mg} / \mathrm{kg})$ in saline (i.p. injection). $A \beta_{1-42}$ oligomers $(3 \mu \mathrm{g} / 3 \mu \mathrm{l})$ were injected intracerebroventricularly (I.C.V., $\mathrm{AP}=-0.1 \mathrm{~mm}, \mathrm{ML}=$ $+1.0 \mathrm{~mm}$ from bregma, $\mathrm{DV}=-2.6 \mathrm{~mm}$ from skull) through Hamilton syringe (26 gauge) [48]. The needle was left for an additional $5 \mathrm{~min}$ after injection in the place to ensure the diffusion of $A \beta_{1-42}$. 


\section{Novel object recognition (NOR) task}

Prior to $A \beta_{1-42}$ injection, mice were habituated to a test arena $(33 \mathrm{~cm} \times 33 \mathrm{~cm} \times 33 \mathrm{~cm})$ without an object for 15 min per day for 2 days. Training was performed 2 days after the stereotaxic surgery. During the training session, mice were placed in the test arena containing two identical objects and allowed to explore the objects for $15 \mathrm{~min}$. Twenty-four hours later, mice were placed again in the same test arena but one of the objects was replaced with a novel object. Behavior was recorded by a video camera. The exploration time to each object was scored manually. The test box was cleaned with $70 \%$ ethanol between each trial. The experimenter was blinded to the treatments for all the behavioral tests.

\section{Fear conditioning}

Prior to fear conditioning training, mice were acclimated to the testing room for $1 \mathrm{~h}$. Mice were placed in the fear conditioning chamber (Coulbourn Instruments) for $2 \mathrm{~min}$ and received two pairs of a tone $(2800 \mathrm{~Hz}, 85 \mathrm{~dB}, 30 \mathrm{~s})$ and a co-terminating electric foot-shock $(0.7 \mathrm{~mA}, 2 \mathrm{~s})$ with $30 \mathrm{~s}$ intervals. One day after the training, mice were placed again in the chamber to test contextual fear memory for $3 \mathrm{~min}$. The freezing behavior was automatically measured by Freeze Frame software (ActiMetrics, IL, USA). Data from one mouse that had freezing rate of deviation more than 2 standard deviations were excluded from the analysis.

\section{Electrophysiology}

Field excitatory postsynaptic potentials (fEPSPs) were performed as previously described [49]. Sagittal hippocampal slices $(400 \mu \mathrm{m}$ thick) were incubated for at least $1 \mathrm{~h}$ in artificial cerebrospinal fluid (ACSF: in mM, 120 $\mathrm{NaCl}, 3.5 \mathrm{KCl}, 2.5 \mathrm{CaCl}_{2}, 1.3 \mathrm{MgSO}_{4}, 1.25 \mathrm{NaH}_{2} \mathrm{PO}_{4}, 10$ D-glucose, $20 \mathrm{NaHCO}_{3}$ )-filled chamber and additional $2 \mathrm{~h}$ in $\mathrm{A} \beta_{1-42}(500 \mathrm{nM})$-treated ACSF-filled chamber before recording. PKRi $(1 \mu \mathrm{M})$ (Calbiochem, Merck Millipore, Billerica, MA) dissolved in ACSF was perfused from $30 \mathrm{~min}$ before LTP induction to $30 \mathrm{~min}$ or $50 \mathrm{~min}$ after LTP induction. fEPSPs were recorded with a platinum-iridium electrode placed in the CA1 striatum radiatum. Bipolar platinum stimulating electrodes were placed in Schaffer-collaterals. LTP was induced by two times high frequency stimulation (2X HFS; 100 pulses at $100 \mathrm{~Hz}$ with $30 \mathrm{~s}$ inter-train interval) or $3 \mathrm{X}$ theta burst stimulation (TBS; 4 pulses at $100 \mathrm{~Hz}$ repeated with $200 \mathrm{~ms}$ inter-burst intervals) protocol. To determine whether the magnitude of LTP differed significantly among groups, the average fEPSP slopes of $40-50$ or 50-60 min after LTP induction from each group were compared. Data were acquired and analyzed by using WinLTP (WinLTP Ltd., ver 2.20b). The experimenter was blinded to the genotypes and treatments.

\section{Western blotting}

Hippocampi were dissected 30 min after i.p. injection of PKRi in $A \beta_{1-42}$-injected mice and $1 \mathrm{~h}$ after PKRi injection in 5XFAD mice. Each hippocampus was homogenized in $150 \mu \mathrm{l}$ lysis buffer containing $10 \mathrm{mM}$ Tris- $\mathrm{HCl}$ (pH 6.8) buffer, 1.6\% SDS, protease inhibitor and phosphatase inhibitors. $1 \mu \mathrm{g}$ of the purified $A \beta_{1-42}$ oligomers for I.C.V. injection or 20-30 $\mu$ g of protein samples from 5XFAD mice and $A \beta_{1-42}$-injected mice were run on a $4-$ $12 \%$ bis tris gel and transferred to a PVDF membrane for $A \beta_{1-42}$ or nitrocellulose membrane for other proteins. After blocking in 5\% skim milk in 0.1\% TBST, membranes were probed with primary antibody (mouse anti-A $\beta$ (4G8), 1:1000, Biolegend, SIG-39220; rabbit anti-p-eIF2 $\alpha$ antibody, 1:1000, Cell signaling, 3597S; rabbit anti-p-PKR, 1:1000, ThermoFisher, 44-668G; rabbit anti-eIF2 $\alpha, 1: 1000$, Cell signaling, 5324S; rabbit anti-p-CREB,1:1000, Millipore, 06-519; rabbit antiCREB, 1:1000, Cell signaling, 9197S; mouse antiGAPDH, 1:10,000, Millipore, MAB374) overnight at $4^{\circ}$ C. After washing 3 times in $0.1 \%$ TBST, membranes were probed with horseradish peroxidase-conjugated secondary IgG for $1 \mathrm{~h}$ at room temperature. Signals from membranes were detected by using ECL chemiluminescence substrate kit (Thermo Pierce). Proteins were normalized to GAPDH, and phosphorylated proteins were normalized to their respective total proteins.

\section{Statistics}

Effects of PKRi treatment on different groups were analyzed by using two-way ANOVA followed by appropriate post-hoc tests. Some behavioral, electrophysiological and western blotting data were analyzed by using unpaired two-tailed t-test as indicated in the results section. Data are presented as mean \pm standard error of the mean (SEM).

\section{Additional files}

\section{Additional file 1: Figure S1. Confirmation of $A \beta_{1-42}$ oligomerization. Figure S2. Inhibition of PKR restores basal synaptic dysregulation in 5XFAD mice. Figure S3. ICR mice showed the low standard of the freezing behavior in contextual fear conditioning. Figure S4. Neither $A \beta_{1-42}$ nor PKRi affected basal synaptic transmission and short-term synaptic plasticity. Figure S5. High frequency stimulation (HFS)-induced LTP is normal in 5XFAD mice. (DOCX $709 \mathrm{~kb}$ )}

\footnotetext{
Abbreviations

ACSF: Artificial cerebrospinal fluid; AD: Alzheimer's disease; ANOVA: Analysis of variance; ATF4: Activating transcriptional factor 4; $A \beta$ : Amyloid $\beta$; CFC: Contextual fear conditioning; CREB: CAMP responsive element binding protein; elF2a: Eukaryotic translation initiation factor 2a; FAD: Familial Alzheimer's disease; fEPSP: Field excitatory postsynaptic potential; GAPDH: Glyceraldehyde 3-phosphate dehydrogenase; HFS: High frequency stimulation; i.c.v.: Intracerebroventricular; i.p.: Intraperitoneal; LTP: Long-term potentiation; NOR: Novel object recognition; PKR: Protein kinase RNA-activated; PKRi: PKR inhibitor; PPR: Paired pulse facilitation ratio; SEM: Standard error of the mean; TBS: Theta burst stimulation
} 


\section{Acknowledgements}

We thank Dr. Woo Keun Song and Dr. Inhee Mook-Jung for providing us with 5XFAD mice and for comments and discussions, and Dr. Jihoon Jo and Dr. YoungSoo Kim for comments and discussions. We also thank Gaeun Park for assistance with editing the manuscript.

\section{Funding}

This work was supported by a grant of the Korea Health Technology R\&D Project through the Korea Health Industry Development Institute (KHIDI), funded by the Ministry of Health \& Welfare, Republic of Korea (HI14C-1922010014) to Y.-S.L. K.-D.H. was supported by Graduate Research Scholarship from Chung-Ang University in 2015.

\section{Availability of data and materials}

All data generated or analyzed during this study are included in this article and the Additional File 1.

\section{Authors' contributions}

Y.-S.L., S.R., S.J.K. designed the experiments and supervised the research. K.-D.H. performed and analyzed the electrophysiological experiments and western blot experiments. M.S.B. performed and analyzed the behavioral experiments. K.-D.H., M.S.B. and Y.-S.L. wrote the manuscript. All authors read and approved the final manuscript.

\section{Ethics approval}

All the animal experiments were approved by the Seoul National University Institutional Animal Care and Use Committee (SNU IACUC) and the Chung-Ang University Institutional Animal Care and Use Committee (CAU IACUC).

\section{Consent for publication}

Not applicable.

\section{Competing interests}

The authors declare no conflict of interest.

\section{Publisher's Note}

Springer Nature remains neutral with regard to jurisdictional claims in published maps and institutional affiliations.

\section{Author details}

'Department of Life Science, College of Natural Science, Chung-Ang University, Seoul 06974, Republic of Korea. ${ }^{2}$ Department of Physiology, Seoul National University College of Medicine, Seoul 03080, Republic of Korea. ${ }^{3}$ Department of Biomedical Sciences, Seoul National University College of Medicine, Seoul 03080, Republic of Korea. ${ }^{4}$ Neuroscience Research Institute, Seoul National University College of Medicine, Seoul 03080, Republic of Korea.

\section{Received: 28 August 2017 Accepted: 19 November 2017} Published online: 13 December 2017

\section{References}

1. Goate A, Chartier-Harlin MC, Mullan M, Brown J, Crawford F, Fidani L, Giuffra $L$, Haynes $A$, Irving $N$, James $L$, et al. Segregation of a missense mutation in the amyloid precursor protein gene with familial Alzheimer's disease. Nature. 1991;349:704-6.

2. Schellenberg GD, Bird TD, Wijsman EM, Orr HT, Anderson L, Nemens E, White JA, Bonnycastle L, Weber JL, Alonso ME, et al. Genetic linkage evidence for a familial Alzheimer's disease locus on chromosome 14. Science. 1992;258:668-71

3. Levy-Lahad E, Wasco W, Poorkaj P, Romano DM, Oshima J, Pettingell WH, CE Y, Jondro PD, Schmidt SD, Wang K, et al. Candidate gene for the chromosome 1 familial Alzheimer's disease locus. Science. 1995;269:973-7.

4. Hardy J, Higgins G. Alzheimer's disease: the amyloid cascade hypothesis. Science. 1992;256:184-5.

5. Duyckaerts C, Delatour B, Potier MC. Classification and basic pathology of Alzheimer disease. Acta Neuropathol. 2009;118:5-36.

6. O'Connor T, Sadleir KR, Maus E, Velliquette RA, Zhao J, Cole SL, Eimer WA Hitt B, Bembinster LA, Lammich S, et al. Phosphorylation of the translation initiation factor elF2alpha increases BACE1 levels and promotes amyloidogenesis. Neuron. 2008:60:988-1009.

7. Chang RC, Wong AK, Ng HK, Hugon J. Phosphorylation of eukaryotic initiation factor-2alpha (elF2alpha) is associated with neuronal degeneration in Alzheimer's disease. Neuroreport. 2002;13:2429-32.

8. Devi L, Ohno M. Deletion of the elF2alpha kinase GCN2 fails to rescue the memory decline associated with Alzheimer's disease. PLoS One. 2013;8:e77335

9. Ma T, Trinh MA, Wexler AJ, Bourbon C, Gatti E, Pierre P, Cavener DR, Klann E. Suppression of elF2alpha kinases alleviates Alzheimer's disease-related plasticity and memory deficits. Nat Neurosci. 2013;16:1299-305.

10. Devi L, Ohno MPERK. Mediates elF2alpha phosphorylation responsible for BACE1 elevation, CREB dysfunction and neurodegeneration in a mouse model of Alzheimer's disease. Neurobiol Aging. 2014;35:2272-81.

11. Mouton-Liger F, Paquet C, Dumurgier J, Bouras C, Pradier L, Gray F, Hugon J. Oxidative stress increases BACE1 protein levels through activation of the PKR-elF2alpha pathway. Biochim Biophys Acta. 2012;1822:885-96.

12. Mamada N, Tanokashira D, Hosaka A, Kametani F, Tamaoka A, Araki W. Amyloid beta-protein oligomers upregulate the beta-secretase, BACE1, through a post-translational mechanism involving its altered subcellular distribution in neurons. Mol Brain. 2015:8:73.

13. Ohno M. Roles of elF2alpha kinases in the pathogenesis of Alzheimer's disease. Front Mol Neurosci. 2014;7:22.

14. Tanokashira D, Mamada N, Yamamoto F, Taniguchi K, Tamaoka A, Lakshmana MK, Araki W. The neurotoxicity of amyloid beta-protein oligomers is reversible in a primary neuron model. Mol Brain. 2017;10:4

15. Gonzalez GA, Montminy MR, Cyclic AMP. Stimulates somatostatin gene transcription by phosphorylation of CREB at serine 133. Cell. 1989;59:675-80.

16. Bourtchuladze R, Frenguelli B, Blendy J, Cioffi D, Schutz G, Silva AJ. Deficient long-term memory in mice with a targeted mutation of the CAMPresponsive element-binding protein. Cell. 1994;79:59-68.

17. Bartsch D, Casadio A, Karl KA, Serodio P, Kandel ER. CREB1 encodes a nuclear activator, a repressor, and a cytoplasmic modulator that form a regulatory unit critical for long-term facilitation. Cell 1998:95:211-223.

18. Lee YS. Genes and signaling pathways involved in memory enhancement in mutant mice. Mol Brain. 2014;7:43.

19. Costa-Mattioli M, Gobert D, Stern E, Gamache K, Colina R, Cuello C, Sossin W, Kaufman R, Pelletier J, Rosenblum K, et al. elF2alpha phosphorylation bidirectionally regulates the switch from short- to long-term synaptic plasticity and memory. Cell. 2007:129:195-206.

20. Dumurgier J, Mouton-Liger F, Lapalus P, Prevot M, Laplanche JL, Hugon J, Paquet C. Groupe d'Investigation du Liquide Cephalorachidien study N. Cerebrospinal fluid PKR level predicts cognitive decline in Alzheimer's disease. PLoS One. 2013;8:e53587.

21. Zhang F, Romano PR, Nagamura-Inoue T, Tian B, Dever TE, Mathews MB, Ozato K, Hinnebusch AG. Binding of double-stranded RNA to protein kinase PKR is required for dimerization and promotes critical autophosphorylation events in the activation loop. J Biol Chem. 2001;276:24946-58.

22. Zhu PJ, Huang W, Kalikulov D, Yoo JW, Placzek AN, Stoica L, Zhou H, Bell JC, Friedlander MJ, Krnjevic K, et al. Suppression of PKR promotes network excitability and enhanced cognition by interferon-gamma-mediated disinhibition. Cell. 2011;147:1384-96.

23. Stern E, Chinnakkaruppan A, David O, Sonenberg N, Rosenblum K. Blocking the elF2alpha kinase (PKR) enhances positive and negative forms of cortexdependent taste memory. J Neurosci. 2013:33:2517-25.

24. Segev Y, Barrera I, Ounallah-Saad H, Wibrand K, Sporild I, Livne A, Rosenberg T, David O, Mints M, Bramham CR, et al. PKR inhibition rescues memory deficit and ATF4 overexpression in ApoE epsilon4 human replacement mice. J Neurosci. 2015;35:12986-93.

25. Oakley H, Cole SL, Logan S, Maus E, Shao P, Craft J, Guillozet-Bongaarts A, Ohno M, Disterhoft J, Van Eldik L, et al. Intraneuronal beta-amyloid aggregates, neurodegeneration, and neuron loss in transgenic mice with five familial Alzheimer's disease mutations: potential factors in amyloid plaque formation. J Neurosci. 2006:26:10129-40.

26. Kim HY, Kim HV, Jo S, Lee CJ, Choi SY, Kim DJ, Kim Y. EPPS rescues hippocampus-dependent cognitive deficits in APP/PS1 mice by disaggregation of amyloid-beta oligomers and plaques. Nat Commun. 2015;6:8997.

27. Kimura R, Ohno M. Impairments in remote memory stabilization precede hippocampal synaptic and cognitive failures in 5XFAD Alzheimer mouse model. Neurobiol Dis. 2009;33:229-35. 
28. Holland PC, Bouton ME. Hippocampus and context in classical conditioning Curr Opin Neurobiol. 1999;9:195-202.

29. Phillips RG, LeDoux JE. Differential contribution of amygdala and hippocampus to cued and contextual fear conditioning. Behav Neurosci. 1992;106:274-85.

30. Frankland PW, Cestari V, Filipkowski RK, McDonald RJ, Silva AJ. The dorsal hippocampus is essential for context discrimination but not for contextual conditioning. Behav Neurosci. 1998;112:863-74.

31. Lee YS, Silva AJ. The molecular and cellular biology of enhanced cognition. Nat Rev Neurosci. 2009;10:126-40.

32. Antunes M, Biala G. The novel object recognition memory: neurobiology, test procedure, and its modifications. Cogn Process. 2012;13:93-110.

33. Bevins RA, Besheer J. Object recognition in rats and mice: a one-trial nonmatching-to-sample learning task to study 'recognition memory. Nat Protoc. 2006;1:1306-11.

34. Figueiredo CP, Clarke JR, Ledo JH, Ribeiro FC, Costa CV, Melo HM, MotaSales AP, Saraiva LM, Klein WL, Sebollela A, et al. Memantine rescues transient cognitive impairment caused by high-molecular-weight abeta oligomers but not the persistent impairment induced by low-molecularweight oligomers. J Neurosci. 2013;33:9626-34.

35. Walsh DM, Klyubin I, Fadeeva JV, Cullen WK, Anwyl R, Wolfe MS, Rowan MJ, Selkoe DJ. Naturally secreted oligomers of amyloid beta protein potently inhibit hippocampal long-term potentiation in vivo. Nature. 2002;416:535-9.

36. Jo J, Whitcomb DJ, Olsen KM, Kerrigan TL, Lo SC, Bru-Mercier G, Dickinson B, Scullion S, Sheng M, Collingridge $G$, et al. Abeta(1-42) inhibition of LTP is mediated by a signaling pathway involving caspase-3, Akt1 and GSK-3beta. Nat Neurosci. 2011;14:545-7.

37. Costa-Mattioli M, Gobert D, Harding H, Herdy B, Azzi M, Bruno M, Bidinosti M, Ben Mamou C, Marcinkiewicz E, Yoshida M, et al. Translational control of hippocampal synaptic plasticity and memory by the elF2alpha kinase GCN2. Nature. 2005:436:1166-73.

38. Pittenger C, Huang YY, Paletzki RF, Bourtchouladze R, Scanlin H, Vronskaya S, Kandel ER. Reversible inhibition of CREB/ATF transcription factors in region CA1 of the dorsal hippocampus disrupts hippocampus-dependent spatial memory. Neuron. 2002;34:447-62

39. Davis GW, Schuster CM, Goodman CS. Genetic dissection of structural and functional components of synaptic plasticity. III. CREB is necessary for presynaptic functional plasticity. Neuron. 1996;17:669-79.

40. Yiu AP, Rashid AJ, Josselyn SA. Increasing CREB function in the CA1 region of dorsal hippocampus rescues the spatial memory deficits in a mouse model of Alzheimer's disease. Neuropsychopharmacology. 2011;36:2169-86.

41. Paesler K, Xie K, Hettich MM, Siwek ME, Ryan DP, Schroder S, Papazoglou A, Broich K, Muller R, Trog A, et al. Limited effects of an elF2alphaS51A allele on neurological impairments in the 5xFAD mouse model of Alzheimer's disease. Neural Plast. 2015;2015:825157.

42. Wu Z, Guo Z, Gearing M, Chen G. Tonic inhibition in dentate gyrus impairs long-term potentiation and memory in an Alzheimer's [corrected] disease model. Nat Commun. 2014:5:4159.

43. Costa RM, Federov NB, Kogan JH, Murphy GG, Stern J, Ohno M, Kucherlapati $R$, Jacks T, Silva AJ. Mechanism for the learning deficits in a mouse model of neurofibromatosis type 1. Nature. 2002:415:526-30.

44. Muller M, Fontana A, Zbinden G, Gahwiler BH. Effects of interferons and hydrogen peroxide on CA3 pyramidal cells in rat hippocampal slice cultures. Brain Res. 1993;619:157-62.

45. Abbott A, Dolgin E. Failed Alzheimer's trial does not kill leading theory of disease. Nature. 2016;540:15-6.

46. Hawkes N. Merck ends trial of potential Alzheimer's drug verubecestat. BMJ. 2017;356:j845.

47. Sevigny J, Chiao P, Bussiere T, Weinreb PH, Williams L, Maier M, Dunstan R, Salloway S, Chen T, Ling Y, et al. The antibody aducanumab reduces Abeta plaques in Alzheimer's disease. Nature. 2016:537:50-6.

48. Kim HY, Lee DK, Chung BR, Kim HV, Kim Y. Intracerebroventricular injection of amyloid-beta peptides in normal mice to acutely induce Alzheimer-like cognitive deficits. J Vis Exp. 2016;

49. Kang M, Ryu H-H, Lee Y-S. Comparisons of behavior and synaptic plasticity among three C57BL/6 substrains. Animal Cells and Systems. 2015;19:181-7.

\section{Submit your next manuscript to BioMed Central and we will help you at every step:}

- We accept pre-submission inquiries

- Our selector tool helps you to find the most relevant journal

- We provide round the clock customer support

- Convenient online submission

- Thorough peer review

- Inclusion in PubMed and all major indexing services

- Maximum visibility for your research

Submit your manuscript at www.biomedcentral.com/submit
C Biomed Central 